Supplementary Materials for

\title{
Oxidation of Isoprene by Neutral Iron Oxide Nanoclusters in the Gas Phase
}

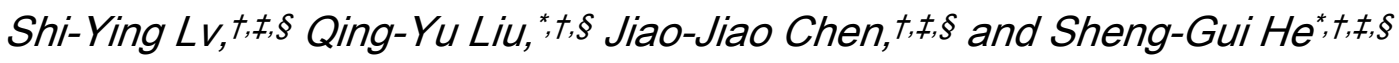

TState Key Laboratory for Structural Chemistry of Unstable and Stable Species, Institute of Chemistry, Chinese Academy of Sciences, Beijing 100190, P. R. China ‡University of Chinese Academy of Sciences, Beijing 100049, P. R. China §Beijing National Laboratory for Molecular Sciences and CAS Research/Education Center of Excellence in Molecular Sciences, Beijing 100190, P. R. China 
Table S1. The reaction channels of neutral $\mathrm{Fe}_{x} \mathrm{O}_{y}$ clusters with isoprene and the pseudo first-order rate constants $\left(k_{1}\right)$ and the average rate constants $\overline{k_{1}}$ (in $10^{-10} \mathrm{~cm}^{3}$ molecule $\left.\mathrm{s}^{-1}\right)$.

\begin{tabular}{|c|c|c|c|c|c|c|c|}
\hline \multirow{2}{*}{$x$} & \multirow{2}{*}{$y$} & \multicolumn{4}{|c|}{ Reaction Channels $^{[a]}$} & \multirow{2}{*}{$k_{1}$} & \multirow{2}{*}{$\overline{k_{1}}$} \\
\hline & & (1) & (2) & (3) & (4) & & \\
\hline \multirow[t]{2}{*}{4} & 6 & $\sqrt{ }$ & $\sqrt{1}$ & $\sqrt{1}$ & $\sqrt{ }$ & 2.4 & \multirow{2}{*}{2.1} \\
\hline & 7 & $\sqrt{ }$ & $\sqrt{ }$ & $\sqrt{ }$ & $x$ & 1.7 & \\
\hline 5 & $\begin{array}{l}7 \\
8\end{array}$ & $\begin{array}{l}\sqrt{ } \\
\sqrt{ }\end{array}$ & $\begin{array}{l}\sqrt{ } \\
\sqrt{ }\end{array}$ & $\bar{x}$ & $\begin{array}{l}\sqrt{ } \\
\end{array}$ & 2.3 & 2.1 \\
\hline \multirow{2}{*}{6} & 9 & $\sqrt{ }$ & $\sqrt{ }$ & $\frac{1}{4}$ & $\frac{1}{1}$ & $\frac{2.0}{16}$ & \multirow{2}{*}{1.3} \\
\hline & 10 & $\sqrt{ }$ & $\sqrt{ }$ & $\sqrt{ }$ & $x$ & 1.0 & \\
\hline \multirow{2}{*}{7} & 10 & $\sqrt{ }$ & $x$ & $x$ & $x$ & 1.4 & \multirow{2}{*}{1.4} \\
\hline & 11 & $\sqrt{ }$ & $\sqrt{ }$ & $\sqrt{ }$ & $x$ & 1.4 & \\
\hline \multirow{2}{*}{8} & 12 & $\sqrt{ }$ & $\sqrt{ }$ & $\sqrt{ }$ & $\mathrm{x}$ & 1.8 & \multirow{2}{*}{1.7} \\
\hline & 13 & $\sqrt{ }$ & $\sqrt{ }$ & $\sqrt{ }$ & $\times$ & 1.6 & \\
\hline \multirow{2}{*}{9} & 14 & $\sqrt{ }$ & $\sqrt{ }$ & $\sqrt{ }$ & $x$ & 1.3 & \multirow{2}{*}{0.9} \\
\hline & 15 & $\sqrt{ }$ & $\sqrt{ }$ & $\sqrt{ }$ & $x$ & 0.6 & \\
\hline \multirow{2}{*}{10} & 15 & $\sqrt{ }$ & $\sqrt{ }$ & $\sqrt{ }$ & $x$ & 1.9 & \multirow{2}{*}{2.0} \\
\hline & 16 & $\sqrt{ }$ & $\sqrt{ }$ & $\sqrt{ }$ & $x$ & 2.0 & \\
\hline \multirow{2}{*}{11} & 16 & $\sqrt{ }$ & $x$ & $x$ & $x$ & 1.5 & \multirow{2}{*}{1.7} \\
\hline & 17 & $\sqrt{ }$ & $\sqrt{ }$ & $\sqrt{ }$ & $\times$ & 1.8 & \\
\hline \multirow{2}{*}{12} & 18 & $\sqrt{ }$ & $\sqrt{ }$ & $\sqrt{ }$ & $x$ & 1.9 & \multirow{2}{*}{2.4} \\
\hline & 19 & $\checkmark$ & $\sqrt{ }$ & $\sqrt{ }$ & $\times$ & 2.8 & \\
\hline \multirow{2}{*}{13} & 19 & $\sqrt{ }$ & $x$ & $\bar{x}$ & $x$ & 2.6 & \multirow{2}{*}{2.5} \\
\hline & 20 & $\sqrt{ }$ & $\sqrt{ }$ & $\sqrt{ }$ & $x$ & 2.5 & \\
\hline \multirow{2}{*}{14} & 21 & $\sqrt{ }$ & $x$ & $\sqrt{ }$ & $\times$ & 3.0 & \multirow{2}{*}{3.0} \\
\hline & 22 & $\sqrt{ }$ & $\sqrt{ }$ & $\sqrt{ }$ & $\times$ & 2.9 & \\
\hline \multirow{2}{*}{15} & 22 & $\sqrt{ }$ & $\times$ & $\sqrt{ }$ & $\times$ & 2.5 & 26 \\
\hline & 23 & $\sqrt{ }$ & $\times$ & $\sqrt{ }$ & $x$ & 2.8 & \\
\hline 16 & 24 & $\sqrt{ }$ & $x$ & $\sqrt{ }$ & $x$ & 3.1 & 30 \\
\hline & 25 & $\sqrt{ }$ & $\times$ & $\sqrt{ }$ & $x$ & 3.0 & \\
\hline 17 & 25 & $\sqrt{ }$ & $x$ & $\sqrt{ }$ & $\times$ & 2.8 & 29 \\
\hline & 26 & $\sqrt{ }$ & $\sqrt{ }$ & $\sqrt{ }$ & $\times$ & 3.0 & \\
\hline 18 & 27 & $\sqrt{ }$ & $x$ & $\sqrt{ }$ & $x$ & 3.1 & 27 \\
\hline & 28 & $\sqrt{ }$ & $\sqrt{ }$ & $\sqrt{ }$ & $\times$ & 2.2 & \\
\hline 19 & 28 & $\sqrt{ }$ & $x$ & $\bar{x}$ & $x$ & 2.9 & 29 \\
\hline & 29 & $\sqrt{ }$ & $\times$ & $\times$ & $x$ & 2.9 & \\
\hline 20 & 30 & $\sqrt{ }$ & $\times$ & $\bar{x}$ & $x$ & 3.1 & 30 \\
\hline 20 & 31 & $\sqrt{ }$ & $X$ & $\times$ & $x$ & 2.9 & 3.0 \\
\hline
\end{tabular}

[a] Reaction channel (1): $\mathrm{Fe}_{x} \mathrm{O}_{y}+\mathrm{C}_{5} \mathrm{H}_{8} \rightarrow \mathrm{Fe}_{x} \mathrm{O}_{y} \mathrm{C}_{5} \mathrm{H}_{8}$

Reaction channel (2): $\mathrm{Fe}_{x} \mathrm{O}_{y}+\mathrm{C}_{5} \mathrm{H}_{8} \rightarrow \mathrm{Fe}_{x} \mathrm{O}_{y-1} \mathrm{C}_{4} \mathrm{H}_{6}+\mathrm{CH}_{2} \mathrm{O}$

Reaction channel (3): $\mathrm{Fe}_{x} \mathrm{O}_{y}+\mathrm{C}_{5} \mathrm{H}_{8} \rightarrow \mathrm{Fe}_{x} \mathrm{O}_{y-1} \mathrm{CH}_{2}+\mathrm{C}_{4} \mathrm{H}_{6} \mathrm{O}$

Reaction channel (4): $\mathrm{Fe}_{x} \mathrm{O}_{y}+\mathrm{C}_{5} \mathrm{H}_{8} \rightarrow \mathrm{Fe}_{x} \mathrm{O}_{y-1} \mathrm{H}_{2}+\mathrm{C}_{5} \mathrm{H}_{6} \mathrm{O}$

The reaction channels with branching ratios higher and less than 5\% are marked by " $\sqrt{ }$ " and " $\times$ ", respectively. 


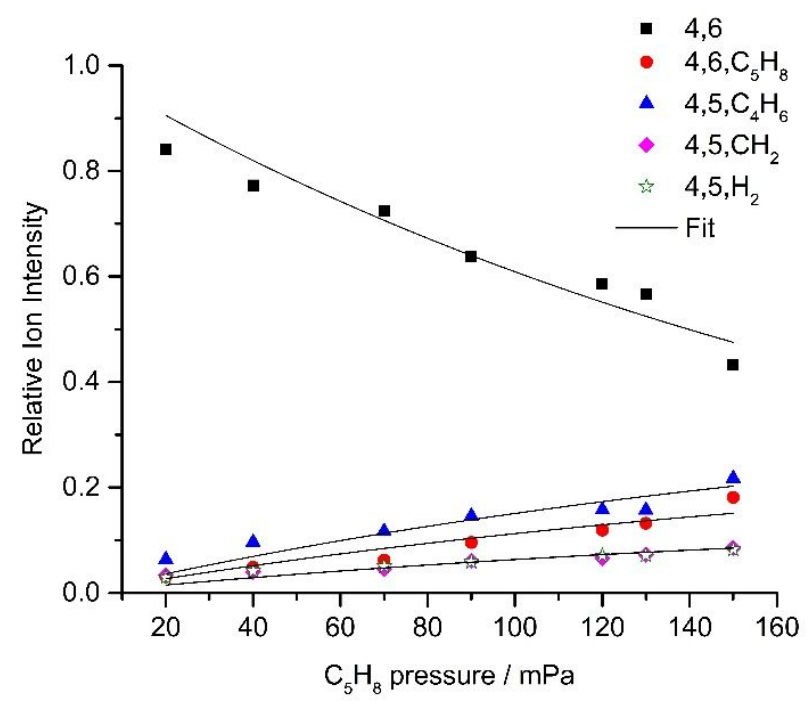

Figure S1. Reaction kinetics for the reaction of $\mathrm{Fe}_{4} \mathrm{O}_{6}+\mathrm{C}_{5} \mathrm{H}_{8}$ with respect to the reactant gas pressure in the experiment. The $\mathrm{Fe}_{x} \mathrm{O}_{y} \mathrm{Z}\left(\mathrm{Z}=\mathrm{C}_{5} \mathrm{H}_{8}, \mathrm{C}_{4} \mathrm{H}_{6}\right.$, etc. $)$ species are labeled as " $x, y, Z$ ".

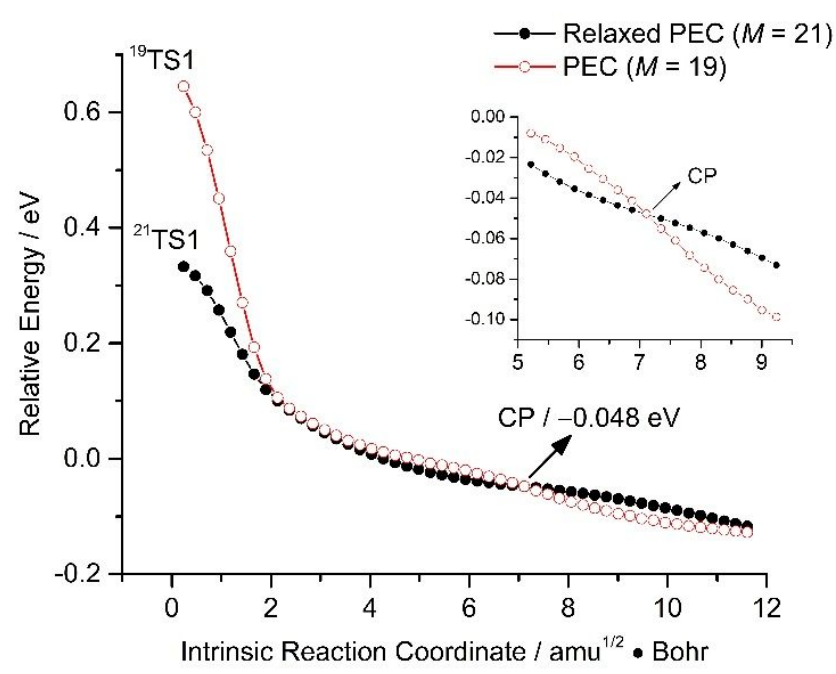

Figure S2. DFT-calculated potential-energy curves (PECs) to indicate the spin conversion point $(\mathrm{CP})$ in Figure 4 of the main text. The filled circle line is the relaxed PECs obtained by IRC calculations starting from ${ }^{21} \mathrm{TS} 1$ to ${ }^{21} \mathrm{I} 2$. The optimized geometries from the filled circle line were used for single-point energy calculations of the spin multiplicity at $19(M=19$, empty circle line). The energy of the CP relative to the separated reactants $\left(\mathrm{Fe}_{4} \mathrm{O}_{6}+\mathrm{C}_{5} \mathrm{H}_{8}\right)$ are given. 

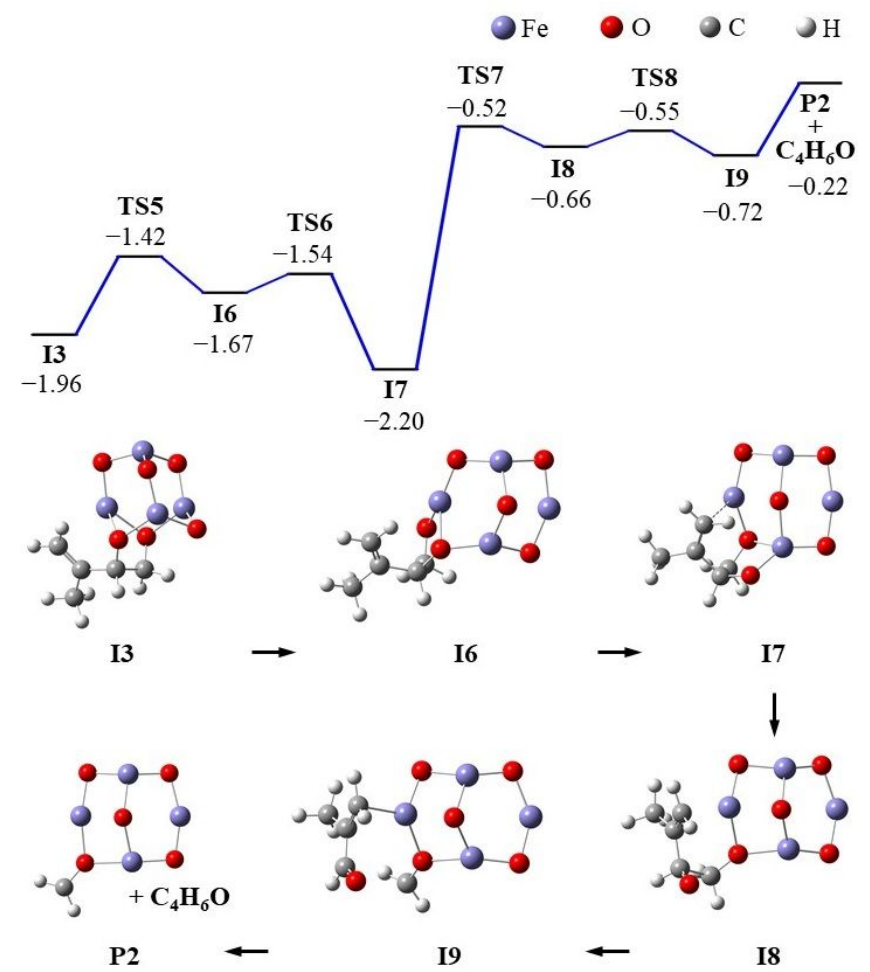

Figure S3. DFT calculated PES for reaction (8): $\mathrm{Fe}_{4} \mathrm{O}_{6}+\mathrm{C}_{5} \mathrm{H}_{8} \rightarrow \mathrm{Fe}_{4} \mathrm{O}_{5} \mathrm{CH}_{2}\left(\mathrm{P}_{2}\right)+$ $\mathrm{C}_{4} \mathrm{H}_{6} \mathrm{O}$.
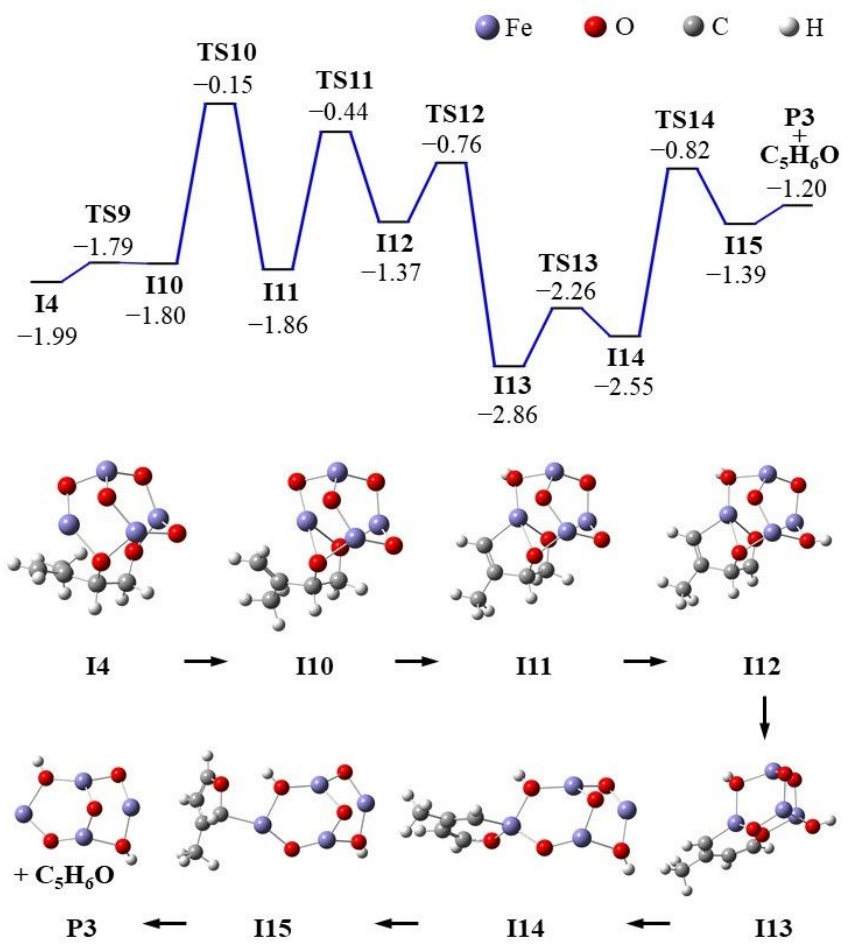

Figure S4. DFT calculated PES for reaction (9): $\mathrm{Fe}_{4} \mathrm{O}_{6}+\mathrm{C}_{5} \mathrm{H}_{8} \rightarrow \mathrm{Fe}_{4} \mathrm{O}_{5} \mathrm{H}_{2}(\mathrm{P} 3)+$ $\mathrm{C}_{5} \mathrm{H}_{6} \mathrm{O}$. 

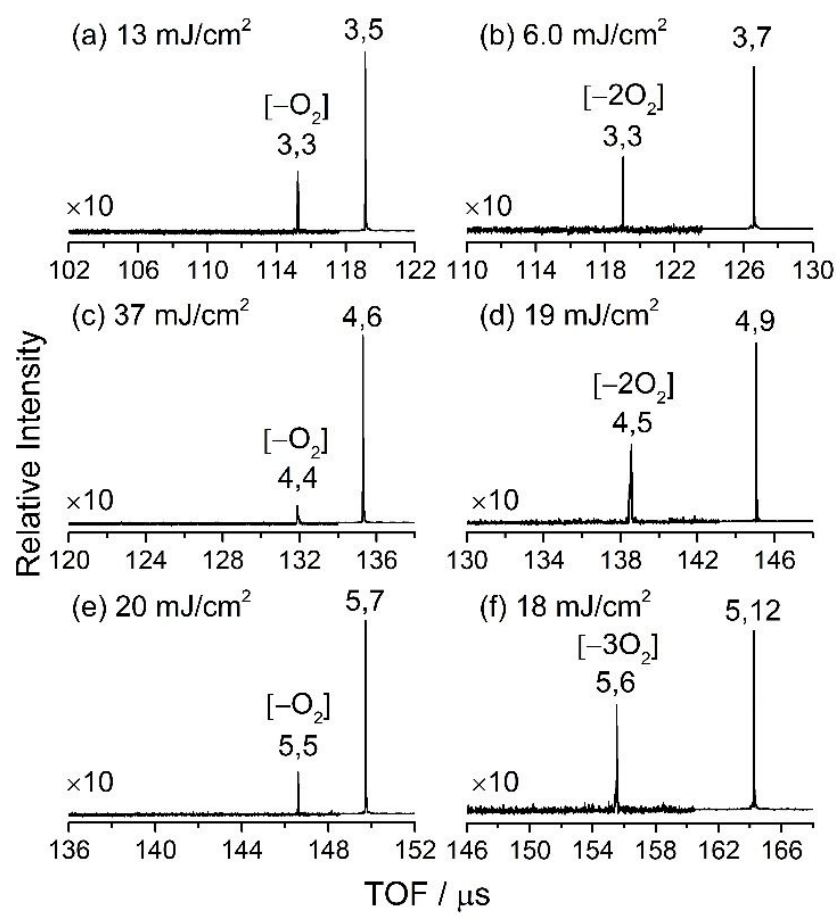

Figure S5. TOF mass spectra for the photo reactions of mass-selected $\mathrm{Fe}_{x} \mathrm{O}_{y}{ }^{+}$at $355 \mathrm{~nm}$. The relative intensities around the product peaks are amplified by a factor of 10 . The clusters $\mathrm{Fe}_{x} \mathrm{O}_{y}^{+}$are labeled as " $x, y$ ". The labels " $-\mathrm{O}_{2}$ ", " $-2 \mathrm{O}_{2}$ ", and " $-3 \mathrm{O}_{2}$ " denote losses of $\mathrm{O}_{2}, 2 \mathrm{O}_{2}$, and $3 \mathrm{O}_{2}$ from the parent clusters, respectively. The laser fluences in $\mathrm{mJ} / \mathrm{cm}^{2}$ are given. 


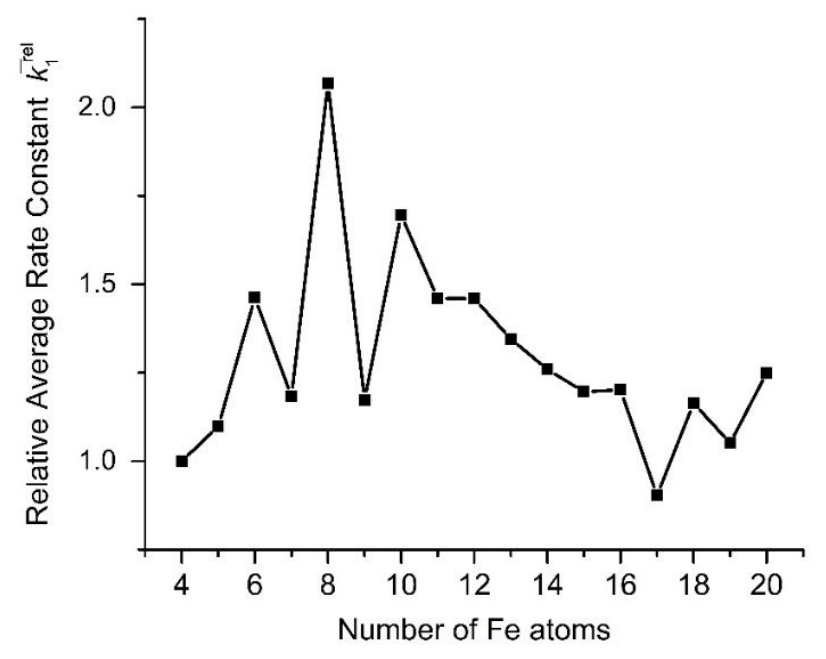

Figure S6. Relative average rate constants $\overline{k_{1}^{\text {rel }}}$ of iron oxide cluster cations $\left(\mathrm{Fe}_{x} \mathrm{O}_{y}^{+}\right)$ with $\mathrm{C}_{5} \mathrm{H}_{8}$. The $\overline{k_{1}}{ }^{\text {rel }}$ value of $\mathrm{Fe}_{4} \mathrm{O}_{y}{ }^{+}$is scaled to unit. 


\section{An estimation of the reaction rate of atmospheric iron oxide nanoparticles.}

The abundance of iron oxide nanoparticles over East Asia at different altitude were measured by a modified single-particle soot photometer. ${ }^{1}$ Within the observed size domain of $170 \mathrm{~nm} \leq D_{\mathrm{m}} \leq 2100 \mathrm{~nm}$, the size-resolved number concentration of iron oxide nanoparticles was approximated using a power function with an offset

$$
\left(\frac{d N}{d \log D_{m}}\right)_{\mathrm{FeO}_{x}}=y_{0}+a D_{m}^{-p}
$$

where $y_{0}, a$ and $p$ are numerical parameters given in ref 1 and listed in Table S2. Assuming that the active sites increase with the particle surface area, we have:

$$
d r=k_{1} \times d N_{\mathrm{FeO}_{x}}=k_{1(1 \mathrm{~nm})}\left(\frac{D_{m}}{1 \mathrm{~nm}}\right)^{2} d N_{\mathrm{FeO}_{x}}=k_{1(1 \mathrm{~nm})}\left(\frac{D_{m}}{1 \mathrm{~nm}}\right)^{2}\left(y_{0}+a D_{m}^{-p}\right) d \log D_{m}
$$

If the diameters of iron oxide nanoparticles are 170-2100 nm, then

$$
r=\left.\frac{y_{0} k_{1(1 \mathrm{~nm})}}{2 \ln 10 \times(1 \mathrm{~nm})^{2}} D_{m}^{2}\right|_{170 \mathrm{~nm}} ^{2100 \mathrm{~mm}}+\left.\frac{a k_{1(1 \mathrm{~nm})}}{(2-p) \ln 10 \times(1 \mathrm{~nm})^{2}} D_{m}^{(2-p)}\right|_{170 \mathrm{~nm}} ^{2100 \mathrm{~nm}}
$$

If the diameters of iron oxide nanoparticles change from $1 \mathrm{~nm}$ to $2100 \mathrm{~nm}$, then

$$
r=\left.\frac{y_{0} k_{1(1 \mathrm{~nm})}}{2 \ln 10 \times(1 \mathrm{~nm})^{2}} D_{m}^{2}\right|_{1 \mathrm{~nm}} ^{2100 \mathrm{~nm}}+\left.\frac{a k_{1(1 \mathrm{~nm})}}{(2-p) \ln 10 \times(1 \mathrm{~nm})^{2}} D_{m}^{(2-p)}\right|_{1 \mathrm{~nm}} ^{2100 \mathrm{~nm}}
$$

The $k_{1(1 \mathrm{~nm})}$ is taken as the average $k_{1}$ of $\mathrm{Fe}_{18} \mathrm{O}_{27}, \mathrm{Fe}_{18} \mathrm{O}_{28}, \mathrm{Fe}_{19} \mathrm{O}_{28}, \mathrm{Fe}_{19} \mathrm{O}_{29}, \mathrm{Fe}_{20} \mathrm{O}_{30}$, and $\mathrm{Fe}_{20} \mathrm{O}_{31}$ clusters with $\mathrm{C}_{5} \mathrm{H}_{8}$ and $k_{1(\mathrm{~nm})}=2.8 \times 10^{-10} \mathrm{~cm}^{3}$ molecule $\mathrm{e}^{-1} \mathrm{~s}^{-1}$. 
Table S2. The $y_{0}, a$ and $p$ values from ref 1 .

\begin{tabular}{cccc}
\hline Altitude & $y_{0}$ & $a$ & $p$ \\
\hline Dry PBL air $^{[\mathrm{a}]}$ & -0.03950 & 17340 & 1.627 \\
$0-1 \mathrm{~km}$ & -0.02937 & 38140 & 1.795 \\
$1-2 \mathrm{~km}$ & -0.02141 & 2488 & 1.465 \\
$2-4 \mathrm{~km}$ & -0.01328 & 585.0 & 1.336 \\
$4-6 \mathrm{~km}$ & -0.02993 & 3.874 & 0.6301 \\
$6-8 \mathrm{~km}$ & -0.02064 & 1.284 & 0.5271 \\
\hline
\end{tabular}

[a] The "Dry PBL air" is the condition to get the experimental parameters for the planetary boundary layer (PBL) over eastern China without experiencing wet removal of aerosols. ${ }^{1}$

Table S3. The estimated reaction rates of iron oxide nanoparticles with $\mathrm{C}_{5} \mathrm{H}_{8} \cdot{ }^{[a]}$

\begin{tabular}{ccc}
\hline Altitude & Rate $/ \mathrm{s}^{-1}(170 \mathrm{~nm}-2100 \mathrm{~nm})$ & Rate $/ \mathrm{s}^{-1}(1 \mathrm{~nm}-2100 \mathrm{~nm})$ \\
\hline Dry PBL air & $4.9 \times 10^{-5}$ & $8.2 \times 10^{-5}$ \\
$0-1 \mathrm{~km}$ & $3.6 \times 10^{-5}$ & $7.8 \times 10^{-5}$ \\
$1-2 \mathrm{~km}$ & $1.9 \times 10^{-5}$ & $2.8 \times 10^{-5}$ \\
$2-4 \mathrm{~km}$ & $1.0 \times 10^{-5}$ & $1.4 \times 10^{-5}$ \\
$4-6 \mathrm{~km}$ & $3.9 \times 10^{-6}$ & $4.2 \times 10^{-6}$ \\
$6-8 \mathrm{~km}$ & $2.6 \times 10^{-6}$ & $2.8 \times 10^{-6}$ \\
\hline
\end{tabular}

[a] Note that the $k_{1}$ value (Table S1) includes the adsorption of $\mathrm{C}_{5} \mathrm{H}_{8}$ on $\mathrm{Fe}_{x} \mathrm{O}_{y}$ clusters. We assume that the adsorbed $\mathrm{C}_{5} \mathrm{H}_{8}$ on $\mathrm{Fe}_{x} \mathrm{O}_{y}$ particles can eventually be oxidized in the atmosphere, particularly in the case that the particle absorbs the light photons: such as $\mathrm{Fe}_{x} \mathrm{O}_{y} \mathrm{C}_{5} \mathrm{H}_{8}{ }^{+}+\mathrm{h} v \rightarrow \mathrm{Fe}_{x} \mathrm{O}_{y-1} \mathrm{C}_{4} \mathrm{H}_{6}{ }^{+}+\mathrm{CH}_{2} \mathrm{O}^{2}$ 


\section{Reference.}

(1) Moteki, N.; Adachi, K.; Ohata, S.; Yoshida, A.; Harigaya, T.; Koike, M.; Kondo, Y., Anthropogenic Iron Oxide Aerosols Enhance Atmospheric Heating. Nat. Commun. 2017, 8, 15329.

(2) Lv, S.-Y.; Liu, Q.-Y.; Zhao, Y.-X.; Zhang, M.-Q.; Jiang, L.-X.; He, S.-G., Formaldehyde Generation in Photooxidation of Isoprene on Iron Oxide Nanoclusters. J. Phys. Chem. C 2019, 123, 5120-5127. 